\section{Distribution}

5.Broj./Proq./Dept./Div.: Pripect -

8. Onfinator Remarks:
3. From: (Originating Organization)

IEMC \& RME Engineering

FFTF Engineering

\section{H18220 BI93AN}

6. Design Authgrity/Design Agent/Cog. Engr.

EFTF

Dan Authoity Design Agen

This document is being routed for approval and release.

11. Receiver Remarks:

11A. Design Baseline Document? $\square$ Yes $\square$ No

1. EDT

Page 1 of $\frac{1}{-1}$
7007

4. Reisted EDT No.

N/A

7. Purchase Order No.

N/A

9. Equip./Component No.:

ID69

10. Systom/Bidg. /F acility

405/FFTF

12. Major Assm. Dwg. No.:

N/A

13. Permit/Permit Application No:

$N / A$

14. Required Response Date:

9/19/96

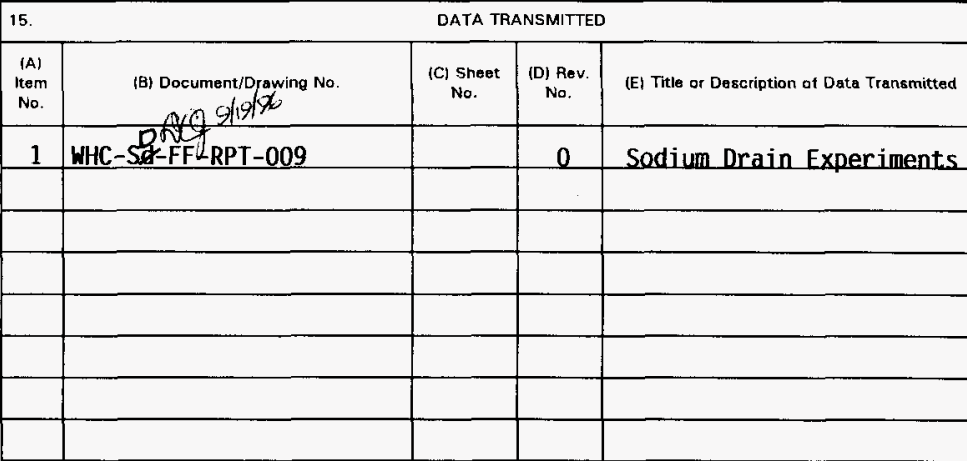

16.

KEY

\begin{tabular}{c|c|c|c}
$|F|$ & $(G)$ & $(H)$ & (I) \\
\hline $\begin{array}{c}\text { Approval } \\
\text { Desig- } \\
\text { nator }\end{array}$ & $\begin{array}{c}\text { Reason } \\
\text { for Trens- } \\
\text { mittal }\end{array}$ & $\begin{array}{c}\text { Origi- } \\
\text { nator } \\
\text { Ditpo- } \\
\text { stion }\end{array}$ & $\begin{array}{c}\text { Receiv } \\
\text { or } \\
\text { Dispo } \\
\text { sition }\end{array}$ \\
\hline
\end{tabular}

\begin{tabular}{|ll} 
& Disposition (H) \& (I) \\
\hline 1. Approved & 4. Reviewed no/comment \\
2. Approved w/comment & 5. Reviewed w/comment \\
3. Disapproved w/comment & 6. Receipt acknowledged
\end{tabular}

17.

\begin{tabular}{|c|c|c|}
\hline $\begin{array}{c}\text { [G] } \\
\text { Reg- } \\
\text { son }\end{array}$ & $\begin{array}{c}\text { (H) } \\
\text { Disp. }\end{array}$ & (J) Name $\quad(1)$ (K) Signature (L) Date (M) MSIN \\
\hline 1 & 1 & Design Authority DC Johnston N/ $\mathrm{NZ}$ \\
\hline & & Design Agent \\
\hline 1 & I & Cog. Eng. MC Johnston \\
\hline 1 & 1 & cog. Morylotic SH Hiller $9 / 18 / 96 \quad \sqrt{2}-02$ \\
\hline & & $\alpha A$ \\
\hline & & Safety \\
\hline & & En \\
\hline
\end{tabular}

18.

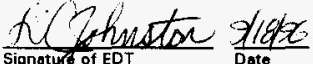

Originator DC EDT Johnston
19.

\section{N/A} Authorized Representative for Receiving Organization

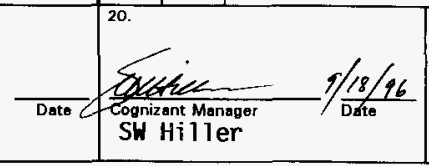

(K) Signature

(i.) Date

(M) MSIN
21. DOE APPROVAL (it required)

Cut No.

$\square$ Approved

$\square$ Approved w/comments

$\square$ Disapproved w/comments 


\section{ID-69 SODIUM DRAIN EXPERIMENTS}

Daniel C. Johnston

Westinghouse Hanford Co., Richland, WA 99352

U.S. Department of Energy Contract DE-AC06-87RL 10930

EDT/ECN: 702607

UC: 506

Org Code: 18220

B\&R Code: EX70

Charge Code: B93AN

Tota1 Pages : 26

Key Words: ID-69, Sodium, Sodium Remova1, FFTF IEM Cel7, Draining of sodium

Abstract: This paper describes experiments to determine the sodium retention and drainage from the two key areas of an ID-69. This information is then used as the initiation point for guidelines of how to proceed with washing an ID-69 in the IEM Cell Sodium Removal System.

TRADEMARK DISCLAIMER. Reference herein to any specific commercial product. proces5, or service by trade name, trademark, manufacturer. or otherwise. does not necessarily constitute or imply its endorsement, recommendation. or favoring by the United States Government or any agency thereof or its contractors or subcontractors.

Printed in the United States of America. To obtain copies of this document, contact WHC/BCS Document Control Services, P.0. Box 1970. Mailstop H6-08. Richiand WA 99352. Phone (509) 372-2420: Fax (509) 376-4989

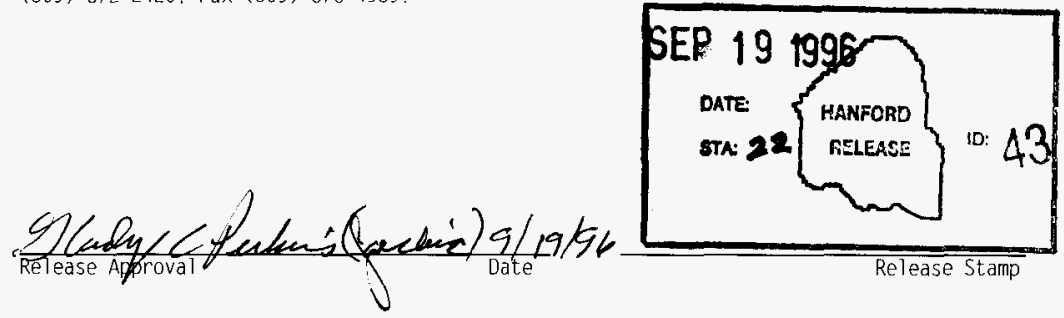

\section{Approved for Public Release}


WHC-SD-FF-RPT-009

Rev. 0

Page 1 of 25

\section{TABLE OF CONTENTS}

1. ID-69 SODIUM DRAIN EXPERIMENTS. .............. 2

A. Background. . . . . . . . . . . . . . . . 2

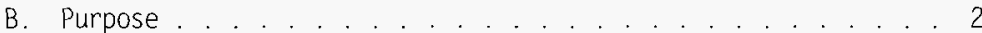

C. Method. . . . . . . . . . . . . . . 2

2. INTERSTITIAL AREAS MODEL SODTUM DRAIN TESTING 3

3. ID-69 SPRING BLOCK SODIUM DRAIN TESTING 4

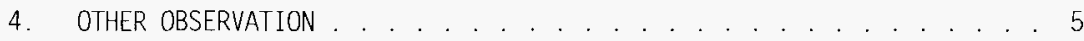

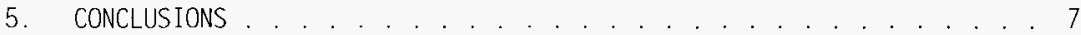

6. Figure 1 - INTERSTITIAL AREA DIMENSIONS . . . . . . . . . 8

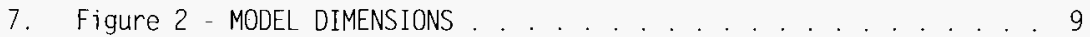

8. ID-69 SODIUM DRAIN DATA SHEET . . . . . . . . . . . . . . 10

9. PICTURES OF THE MODEL OF THE TUBE INTERSTITIAL AREAS . . . . . . . 14

10. PNNL SUMMARY OF ID-69 SODIUM DRAIN . . . . . . . . . 17

11. TEST FOR SODIUM RETENTION OF THE ID-69 SPRING BLOCK . . . . . . . 20

12. PICTURES OF SODIUM RETENTION IN SPRING BLOCK. . . . . . . . . . . 22

13. PNNL SUMMARY OF SODIUM RETENTION IN THE SPRING BLOCK. . . . . . . . 24 
WHC-SD-FF-RPT-009

Rev. 0

Page 2 of 25

\section{ID-69 SODIUM DRAIN EXPERIMENTS}

\section{Background}

Four designs of ID-69s have been used to store spent fue 1 pins in the Fue 1 Storage Facility (FSF), and each of these designs must be demonstrated to be washable in the Sodium Removal System (SRS) as part of the preparation for dry storage.

The Type $C \& D$ models are open compartments where the worst case spacing of the pins is similar to that of a DFA. These models are expected to hold a similar amounts of sodium as a DFA. Based on the experience washing DFAs these do not present any new chal lenges.

The Type A model container is a collection of tubes which are tack welded together at the top of the tubes where the tubes contact. The tubes and the areas between the tubes are open to the wash process. There are more open spaces in this model when compared to DFA spacing.

A type B container has never been made.

The design with the potential for holding the greatest amount of sodium is the original design having 109 tubes welded to a top tube plate and a pin/spring block assembly at the bottom of the tubes. These long narrow spaces could retain sufficient sodium that upon reaction with liquid water could generate pressures which exceed the overpressurization protection analysis limits of the SRS.

\section{Purpose}

The problem which must be resolved is what must be done to ensure safe reliable washing of ID-69s in the SRS? The major concerns become how much sodium will be present and how will it be retained in the original ID-69 design. Experience with DFAs and reflectors has shown the SRS is adaptable to many different conditions if those conditions are known. The purpose of these experiments is to determine how much sodium is retained and determine the retention behavior in order to provide guidelines for the SRS gas injection and rinse process in cleaning these assemblies.

\section{Method}

To establish how much sodium would be held in the 109 tube array, a model was constructed which duplicates the spacing and the interstitial areas between several tubes. See attached figures for the dimensions of the interstitial areas, fig. 1, and the model, fig. 2.

The model was subjected to the same conditions expected by an ID-69 in FSF. where the conditions could not be duplicated, conditions which would cause more sodium to be retained were used. This included performing a manua? withdrawal into a colder atmosphere at a faster rate than that used by the refueling equipment when removing assemblies from FSF into the inert gas space above the sodium. 
WHC-SD-FF-RPT-009

Rev. 0

Page 3 of 25

The sodium melting was done in a glovebox with an argon atmosphere controlled to a maximum of $10 \mathrm{ppm}$ impurities. This makes the atmosphere very simi 7 ar to the atmosphere in FSF. The temperature of the sodium and the argon atmosphere was monitored via a thermocouple system in the glovebox.

\section{INTERSTITIAL AREAS MODEL SODIUM DRAIN TESTING}

The model was placed into sodium at $700^{\circ} \mathrm{F}$ to wet the surfaces. Because of the heat energy placed into the system to reach the automatic set point, the temperature continued to increase to $819^{\circ} \mathrm{F}$. This made the wetting process more instantaneous. Wetting was accomplished in a few minutes and visually verified (see photo bottom pg 14). The sodium was allowed to cool $400^{\circ} \mathrm{F}$. The model was then placed into sodium at $400^{\circ} \mathrm{F}, 450^{\circ} \mathrm{F}, 500^{\circ} \mathrm{F}$, and $600^{\circ} \mathrm{F}$ and allowed to momentarily soak. It was then withdrawn faster than the normal refueling equipment handling speed to determine what effect the sodium temperature had on the drain process. Since there was not a detectable difference in the amount of sodium retained it is concluded the temperature effect was negligible. After each insertion and withdrawal, the model was weighed to determine the amount of sodium retained on the surfaces and in the interstitial areas. This process was observed closely and photographs taken to develop an awareness of the adhering behavior of liquid sodium. The model was inserted into sodium twice at each temperature, when the model was removed the second time it was shaken to determine whether that made a difference to draining behavior. Shaking did not make a discernable difference. This model was compared with a full size ID-69 to determine the scale up factor required to provide a good estimate of the total amount of sodium retained. The model had 8 complete interstitial areas compared to 180 in an ID-69. There are eight half interstitial areas on the model exterioyr and 36 in a full size ID-69. The length of the tubes immersed in sodium was 7.25" for the model and 80.875" for the ID-69 when stored in FSF. This becomes the basis for the following volume ratio:

$$
(180 / 8+36 / 8) 80.875 / 7.25=301.2
$$

The amount of sodium retained by the model was a range from 1.8 grams to 2.3 grams. When this is multiplied by the volume ratio factors above. the amount of sodium retained in the interstitial areas of a full size ID-69 is approximately 542.2 to 692.8 grams. Assume 700 gms.

This assumes the pattern of sodium distribution is repeated each 7.25" as if the models were stacked on top of each other and not allowed to drain from one to the other. This is very conservative behavior, but not very likely.

A more likely distribution pattern will be a stretched version of the model where the top 4" of the model is what the top 76.875" of the ID-69 tube interstitial areas will be. The bottom $3^{\prime \prime}$ of the model is what the bottom $3^{\prime \prime}$ of the ID-69 tube interstitial areas will be. For conservatism, allow this to be 4". To convert the experiment findings to these conditions requires some additional assumptions. Sodium appeared to completely fill the interstitial 
WHC-SD-FF-RPT-009

Rev. 0

Page 4 of 25

areas to a height of about 3 "(see photo pg 15). However, the interstitial areas could not have been filled because the weight of sodium. if filled to 3" without any voids. is 4.36 gms, and the total weight of the sodium retained in the entire model was 2.3 gms. The model bottom $3^{\prime \prime}$ is at best only $50 \%$ filled. By comparison of what can be seen of the sodium it is conservative to estimate $2 / 3$ of the sodium held by the model is in the bottom $3 " .2 / 3$ of 2.3 is 1.533 . When divided by 3 , this amounts to .51 gms per inch. The top $41 / 4$ " of the model then holds $1 / 3$ of the sodium. $1 / 3$ of 2.3 is $.77 \mathrm{gms}$ which when divided by $4.25^{\prime \prime}$ amounts to .181 gms per inch. For an ID-69 this volume of sodium becomes:

$$
\begin{aligned}
& (180 / 8+36 / 8)(80.875-4.0) .181+(180 / 8+36 / 8)(4.0) .51=430.77 \mathrm{gms} \\
& \text { Assume } 431.0 \mathrm{gms}
\end{aligned}
$$

\section{ID-69 SPRING BLOCK SODIUM DRAIN TESTING}

A full sized pin/spring block was also immersed into liquid sodium. However this assembly was not sodium wetted. In discussions which arose after the tube testing the observation was made that in intricate spaces like springs around pins, the nonwetted condition would be the more conservative case retaining more sodium. The 19 pound size of the assembly required a scale that was too large to be taken into the glovebox. Therefore the assembly had to be allowed to cool before seal wrapping for removal and weighing. The block was placed into sodium twice and the amount of sodium retained was 55.84 gms and 53.6 gms. However the change in sodium height in the container was also recorded to cross check the displacement volume, and the spring block displaced a total of $1245.17 \mathrm{cc}$. This is equivalent to the change in height of 2.6" in a 6.1" inside diameter container. The displacement for the block should be 1073.91 cc based upon the weight of the container, density and volume of the 300 series staintess steel and inconel. Therefore an additional $171.26 \mathrm{cc}$ of gas volume was retained, and if the sodium remaining is subtracted, 55.84 or 53.5 gms, the gas space is 115.42 or 117.66 ccs respectively. That meant if the sodium would not completely fill the voids in the spring block, then it probably won't drain from them either. In the FSF, it is assumed these areas will fill because of the very long residence time, greater than one year. and the flow displacement due to the EM pump flow. Conservatively, the amount of sodium retained becomes $171.26 \mathrm{cc}$. Assume $174 \mathrm{gms}$. The volume of $175 \mathrm{gms}$ of sodium is $10.99 \mathrm{in}^{3}$. This becomes either a solid cube 2.2 " on a side or a sphere with a 1.375 radius.

The other areas of the ID-69 are conservatively assumed to be equivalent to a DFA. This is conservative because this style ID-69 will have a maximum of 109 pins and the DFA has 217 pins. Also inlet nozzle of a DFA closely approximates the spring block for sodium retention, but this amount of sodium is not being subtracted. A DFA has been found to retain 200-500 grams sodium. 
WHC-SD-FF-RPT-009

Rev. 0

Page 5 of 25

Adding all these together, assuming the maximum amount of sodium, the amount of sodium in an I0-69 should be less than:

\author{
431 gms (interstitial) \\ 174 gms (spring block) \\ $500 \mathrm{gms}$ (rest of the ID-69) \\ 1105 gms TOTAL
}

\title{
OTHER OBSERVATIONS
}

The model that duplicated the interstitial areas used solid rods for the tubes. A couple of the outer rods assumed skewed positions of approximately an $1 / 8$ inch in the worst case at the bottom of the assembly when welded into the top plate which fixed the top ends. This was assumed to be a conservative error because it would permit the model to hold more sodium than an undistorted model. In reality it did not make any discernable difference in the amount of sodium held, but it did make a difference in the distribution of the sodium. The skewed condition of rods appeared to permit more sodium to drain to the bottom of the model (see photo top pg 14), and it appeared to completely fill the interstitial areas to a height of about $3^{\text {" (see photo pg }}$ 15). Because of gravity and the surface tension properties of sodium what was seen was a nearly complete $f i 1 \mathrm{~m}$ forming in the narrowest part of the interstitial areas. It is reasonable to assume based on visual comparisons that the sodium is more densely collected than the drained regions above. The cross-sectional distribution of sodium in this region is thought to start as a thin film bridging the gaps at the narrowest part of the interstitial area. This film continues to become thicker until it fills a maximum of $50 \%$ of the available area. starting at the narrowest point and filling around the edges toward the center. When the rods were forced into place and held by a hose clamp. the amount of sodium held did not change. The clamp held negligible sodium, and therefore did not affect the data. To estimate height the width of the clamp is .5 inches. The height of the sodium column from the bottom of the model was observed to be approximately two inches (see photo pg 16). This is not as high as the previous skewed condition. This leads to a conjecture that the sodium did not clump together as much, perhaps because of the sodium surface tension and increased surface contact, and therefore was more evenly distributed throughout the model. This is significant because it means the sodium surface available for washing would be greater and more exposed than in the skewed condition. Removal of sodium will go quicker than if the sodium pooled into a closed mass. The ability of the sodium to interact with the tube surface is influenced by the wetted condition.

If the assemblies are not sodium wetted after a least a year of sitting in FSF sodium. how will sodium behave in the unwetted interstitial areas? The conservative approach would be the interstitial areas would be filled with sodium and not drain very wel1, and because of the high surface tension of sodium and the narrowness of the openings it may not drain at a11. Therefore the spring block assembly was to be left unwetted. 
WHC-SD-FF-RPT-009

Rev. 0

Page 6 of 25

The spring block assembly was inserted into sodium in the unwetted condition at $400^{\circ} \mathrm{F}\left(204^{\circ} \mathrm{C}\right)$. It has many sma 71 areas that would retain sodium if it was not going to drain (see photo bottom pg 23). When the assembly was lifted from the sodium and allowed to drain, it was observed the unwetted surfaces appeared to drain easily. As a matter of fact. some of the surfaces of the springs appeared to be coated with sodium as if they had become wetted as the sodium level fell away. In the larger gaps of approx $1 / 8$ inch the sodium drains readily. and in the .020"-.030" gaps of the spring coils some drain or didn't fill and others were still retaining sodium (see photo middle pg 22). This seems to span a 11 the conditions that wi11 most probably exist and indicates at least some of the interstitial areas between tubes and the springs will drain in the unwetted condition too.

Also observed was the way the sodium drained through the spring block assembly. If the block was gently raised from the sodium, the sodium was observed to pool on the flat top of the pins and form into sheets, but if there was any vibration or agitation the sodium very readily flowed off and down between the pins and springs (see photo top pg 22). The normal position of the top pin surfaces will be depressed by the installed pins making larger gaps between the opposite end pin surfaces at the bottom plate and break up the flat collection surface that existed for the test. This means the recorded amount of sodium retained in the test is conservative and higher than will be actually obtained. This also means any vibration or agitation by the fuel handling equipment during the removal of ID-69S from FSF will enhance the drain of sodium from the top of pins and through the spring block assembly.

After removal from the pot, the spring block assembly was placed on several pairs forceps laid on their sides to let the sodium solidify or drain before transport to the scale. After solidification. several pins were pushed to verify the sodium had not blocked flow passages. About $1 / 3$ of the pins were moveable indicating open passages for moist gas flow (see photo bottom pg 22), and there was not any sodium left under the block when it was lifted. This means no sodium drained out of the block once it was removed from the pool. The presence of the gas spaces was verified by shaking the spring block the second time it was totally immersed in sodium. Bubbles could be seen breaking the surface as a result of the escaping gas.

The pot of sodium used to immerse the spring block assembly showed evidences of impurities forming on the surface as the result of off gassing or moisture evaporation from the insulation installed on the pot as the pot was heated (see photo middle pg 23). After the spring assembly was immersed in sodium, the surface of the sodium was much cleaner indicating the sodium reaction products on the sodium surface had been broken up and were dispersed inside or through the spring block assembly (see photo top pg 23). This shows the impurities will not stop drainage.

When the interstitial model and the spring block assembly were heated, they functioned as heat reservoirs that affected the behavior of sodium. The 
WHC-SD-FF-RPT-009

Rev. 0

Page 7 of 25

significance of this behavior is the large heat reservoir inside the tube bundle and the spring assembly will encourage sodium drainage.

The factor that will have the greatest affect on the length of time to remove sodium will be the distribution of the sodium and what the minimum dimension through any closed mass of sodium will be. The drain tests indicate there wi 11 be an open flow path from top to bottom through the ID-69.

The minimum dimension becomes the thickness of the closed mass of sodium in the interstitial areas of the tubes or in the spring block. Respectively. this will be less than 4 " axially for the interstitial tube areas at a $50 \%$ concentration meaning it wi 11 be equivalent to 2 " without voids. Or assume a sphere contains all the sodium in the spring block, and the sphere is accessible on all sides, then a 1.375" radius sphere is the maximum within the spring block assembly. The 1.375 radius becomes the minimum distance. The open 5paces inside the tubes of the tube array and spring block wi17 provide an access path for moist gas and a vent path for hydrogen produced in the moist gas injection process, preventing potential pressure buildup. Previous datal indicate "fairly uniform [sodium-7iquid water] reaction rates" occurred in vertical tubes .187" I.D. or less, when tubes filled with sodium were immersed in water. Lower water temperatures yielded slower rates. This is useful information in the event the moist gas injection process does not react all the adherent sodium.

CONCLUSIONS

1. Sodium drains well from wetted or unwetted assemblies.

2. A flow path will exist through the ID-69 to permit sodium reactions from more than one direction in all spaces, and prevent buildup of hydrogen gas.

3. The worse case total amount of sodium expected in the original design ID-69 is 1105 gms.

4. When individual sodium drain response patterns are combined within an assembly, the actual amount of sodium retained will most likely be much less than the $1105 \mathrm{gm}$ estimate provided above.

5. The maximum dimension for a closed mass of sodium is 2 inches axially in the interstitial areas.

1

1. Annual Technical Progress Report, Sodium Technology and Cover Gas Seal Development Programs; Government Fiscal Year 1974. AJ-AEC-13132, dated August 15, 1974. Atomics International. Division, Rockwell International. 
WHC-SD-FF-RPT-009

Rev. 0

Page 8 of 25

Figure 1

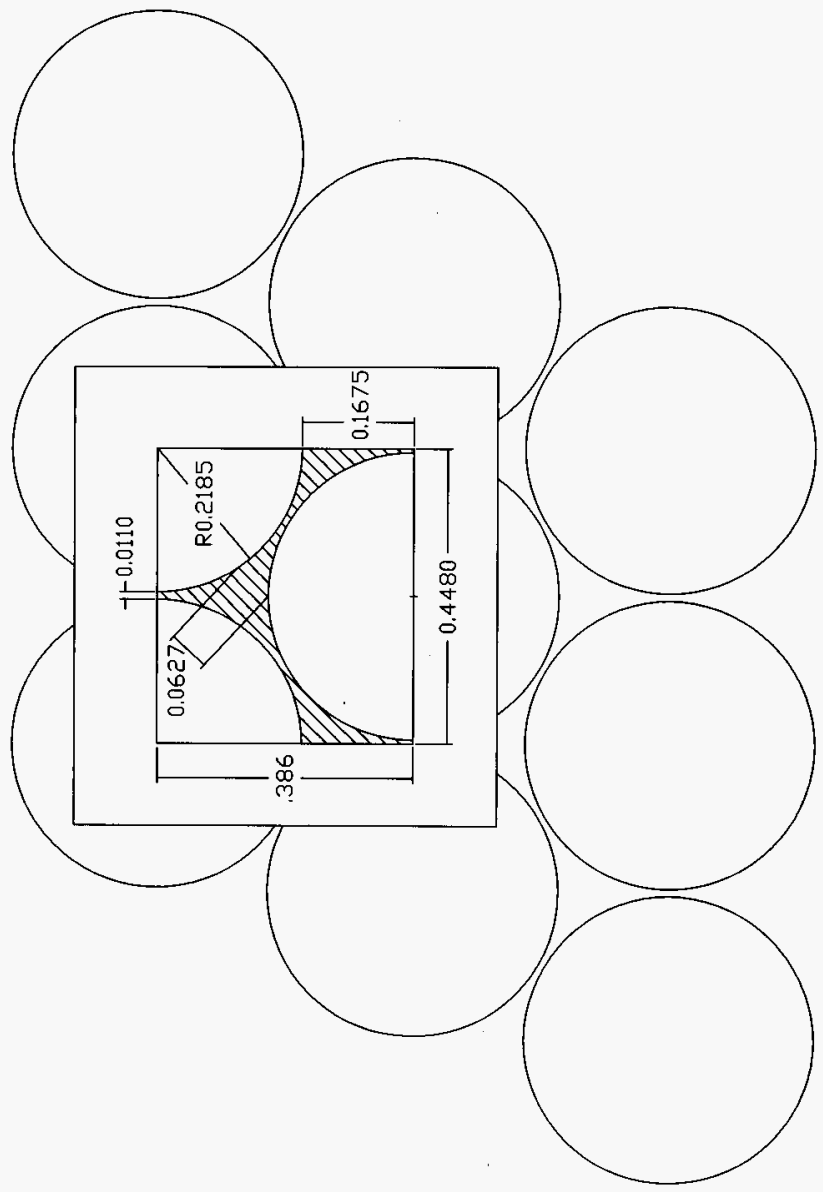




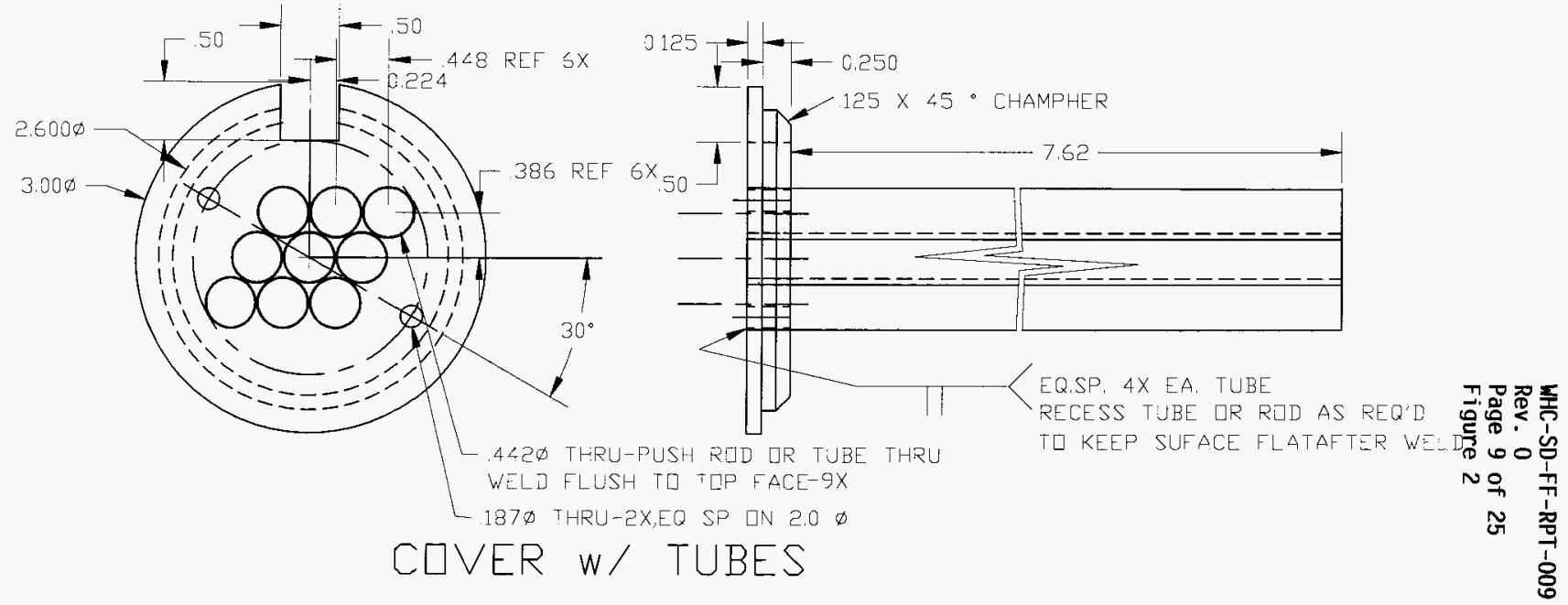




\section{ID-69 SODIUM DRAIN \\ DATA SHEET}

SCOPE

This experiment is an effort to approximate the amount of sodium that is left in the interstitial areas between the tubes of the ID-69 containers.

METHOD

The model is nine rods in a top plate that has been constructed to the same spacing and size as the original tubes using .4375 dia rods rather than 012 wall tubes. This eliminates the concern of how much sodium is on the inside of the tubes. The model wi 11 be weighed before emersion into sodium. This will be compared to the weight of the model after it is sodium wetted and allowed to drain when removed from the sodium. The difference in weight will be the amount of sodium between the tubes.

EQUIPMENT

Type and model scale

Nether PEGOCO

Type of Thermocouple ( $T / C)$

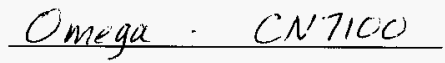

WEIGHT of the ID-69 MODEL

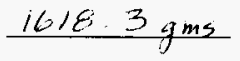

WEIGHT of the Container

$1785.5 \mathrm{gms}$

wit. of Na contaner 2187,5 yms

Weight of sodium in container 402 gms

\section{PROCEDURE}

1. Record the information required for the scale and $T / C$ in the above section.

2. Heat the sodium in the container melting it. Observre the reaction of the surface of the sodium to confirm the condition of the glovebox atmosphere. Record the reaction of the surface i.e. does it cloud or does it clump?

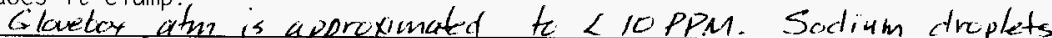

ware exposed in the ligi'd state, and the surface wis observed

to ant cloud oien or form ans lomps or clumps.

3. Continue heating to a mininum of $370^{\circ} \mathrm{C}$ to sodium wet the model. Insert the model into the sodium. Record the wetting temperature and record observations such did any wicking occur?

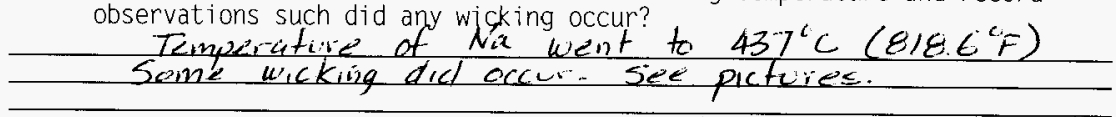


4. Record the approximate distance from the sodium to the top plate. $\approx .375 "$. distance approxmakly equal to thk of plate. (see picture)

5. Allow the sodium to $\operatorname{coo} 7$ to approximately $204^{\circ} \mathrm{C}$. Record temperature. $204^{\circ} \mathrm{C}$

6. Insert the model allow it tos st for 5 min. Withdraw the model at a

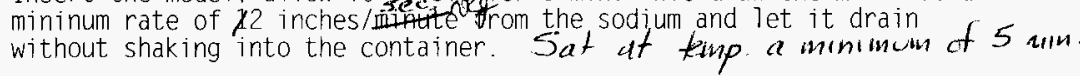

7. Weigh and record the result of the weighing of the model. 1620.6 gins

8. Substract the weight of the model recorded under equipment from the total in step 7 . The difference is the amount of sodium remaining.

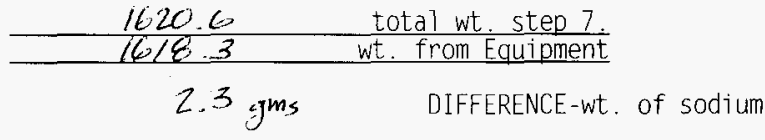

9. Repeat step 6 and shake to encourage sodium drain.

10. Repeat step 7 and 8.

$\frac{1620.5}{16 / 8.3}$ total wt. repeated step 7.10

11. Increase the temperature of the sodium $100^{\circ} \%$. Record temperature. $262^{\circ} \mathrm{C}\left(5 \times 33^{\circ} \mathrm{F}\right)$

12. Repeat steps 6-8. Record total weight. 16,20.1 weight

$\frac{16.20 .1 \text { total wt. step } 12}{1618.3 \text { wt. from Equipment }}$

13. Repeat steps 6-8 and shake. Record total weight. 1620.4 weight

Glowber atm temp $42 \% \mathrm{C}$

1620.4 total wt. step. $12 / 3$ $16 / 6.3$ wt. from Equipment

2. 1 gms DIfFERENCE-wt. of sodium 
14. Repeat steps til it can be determined at what point the temperature begins to improve the sodium drain or it can be established the effect is a straight line phenomen when graphed.

15. If results of step 12 different from step 8 , lower the temperature $32^{\circ} \mathrm{C}$ $\left(50^{\circ} \mathrm{F}\right)$ and repeat steps $6-8$.

16. Decrease the temperature of the sodium approximately $32^{\circ} \mathrm{C}\left(50^{\circ} \mathrm{F}\right)$. Record temperature.

$$
232^{\circ} \mathrm{C}
$$

17. Repeat steps 6-8. Record total weight. $1620.3 g m$ weight see pictures

$\frac{1620 \cdot 3 \cdot \frac{1}{1618 \cdot 3} \text { total wt. step } 17}{2 \cdot 6 \text { froms Equipment }}$

18. Repeat steps 6-8 and shake. Record the temperature. Record total weight. $232^{\circ} \mathrm{C}$ - temperature 1620.5 gmweight

$\frac{16,20.5 \text { total wt. step } 18 .}{16183 \text { wt. from Equipment }}$

19. Increase the temperature of the sodium to approximately $315^{\circ} \mathrm{C}\left(600^{\circ} \mathrm{F}\right)$. Record temperature. $315^{\circ} \mathrm{C}$

20. Repeat steps 6-8. Record total weight. 1620.1 weight

$\frac{\frac{1620.1}{1618.3} \text { total wt. step } 20 .}{1.8 \text { gms }}$


21. Repeat steps 6-8 and shake. Record the temperature. Record tota 1 weight.

$3,9^{\circ} \mathrm{C}$ temperature 1620.1 weight

$\frac{\frac{1620.1 \mathrm{gm} \text { total wt. step } 21 .}{1618.3 \mathrm{wt} \text { from Equipment }}}{1.8 \mathrm{gpa}^{41} \text { DIFFERENCE-wt. of sodium }}$

22. Weight hose flamp and record weight.

27.54 weight

23. Add weight of the clamp to the weight of the model.

$\frac{161 \varepsilon .3 \text { wt. from Equipment }}{27.5 \text { wt. Of clamp }}$

24. Insta 11 hose clamp on to the model at bottom end to attempt to pul1 the rods together.

25. Set the temperature of the sodium to $204^{\circ} \mathrm{C}$. Record temperature.

26. Repeat steps 6-8. Record total weight. 1648.0 weight

$\frac{1648 . \% \text { total wt. step } 26 .}{1645.8 \text { wt. from step } 23}$

27. Remove clamp and repeat steps 6-8. Record total weight. $\frac{1620.6 \text { weight }}{204^{\circ} \mathrm{C} \text { temperatcre }}$ 1620.6 total wt. step 26

$23 \mathrm{gm}$. DIFFERENCE-wt. of sodium

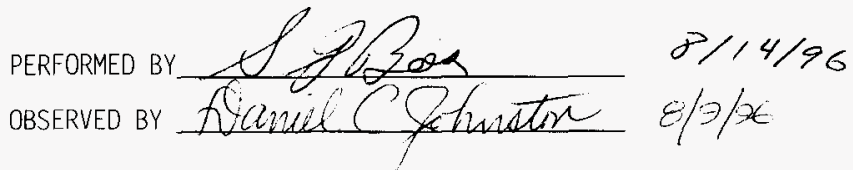



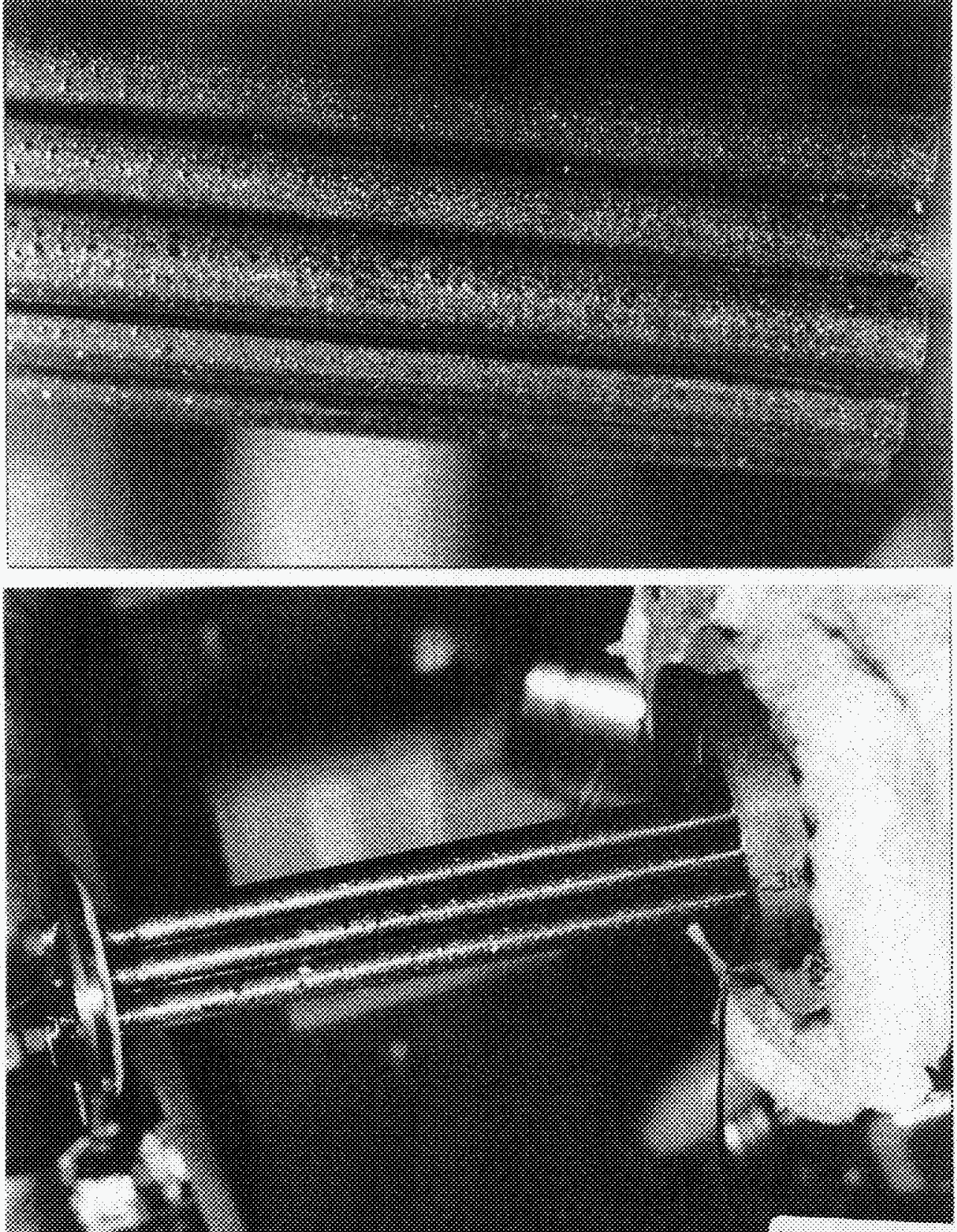

$\$ 36,33,4,0,1,063$ kon, 6 


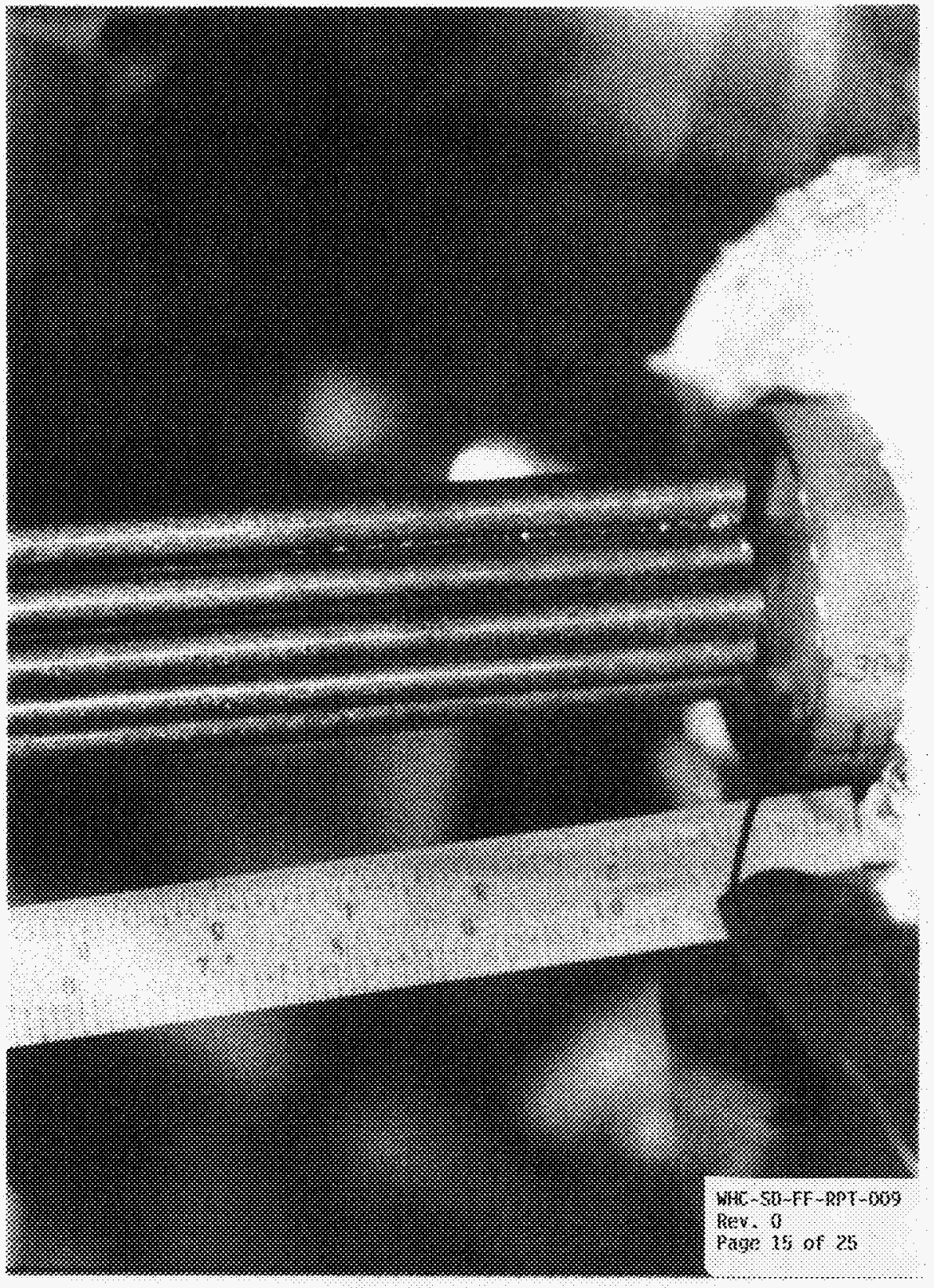



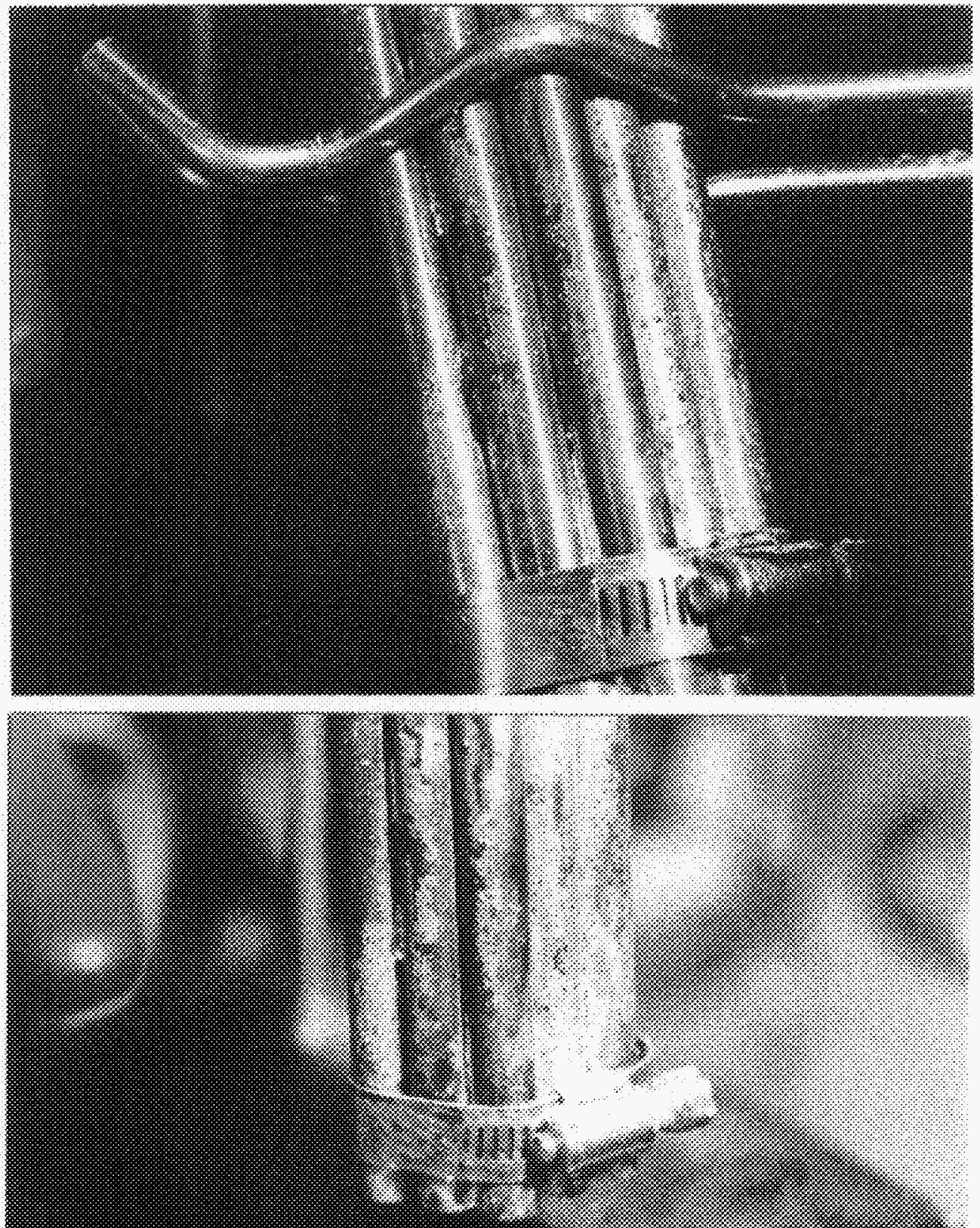
August 13, 1996

D.C. Johnston

Westinghouse Hanford Co.

Box 999 Mail Slot N2-02

Richland, WA 99352

Dear Mr. Johnston:

Sodium drain testing of the ID-69 tube assembly model has been completed. Testing was done in an inert atmosphere glove box containing $<1 \mathrm{ppm}$ oxygen and water. Reagent grade sodium was heated in a bottom draining melter and 402 grams were drained directly into the test container. A 6-kilogram top loading balance was brought into the glove box for weighing the sodium and model during the test.

It was assumed that the ID-69 assembly would be fully wetted by the sodium while in the Fuel Storage Facility (FSF). To duplicate wetted conditions, the model was to be heated to $371^{\circ} \mathrm{C}$ $\left(700^{\circ} \mathrm{F}\right)$ for 30 minutes. Heater overshoot caused the actual wetting temperature to be $437^{\circ} \mathrm{C}$ $\left(819^{\circ} \mathrm{F}\right)$. A visual inspection of the model indicated that wetting had occurred.

Drain testing was performed at $400^{\circ}, 450^{\circ}, 500^{\circ}$ and $600^{\circ} \mathrm{F}$. Of interest was whether the sodium would drain better if the model was shaken as it was removed. Therefore the drain tests were performed twice at each temperature, once removing the model smoothly and a second time while shaking gently. The model was weighed while suspended from a ring stand setting on the balance. At all temperatures tested, sodium held up in the model drained to the bottom half of the fixture, where the spaces between the rods were at their widest. No sodium dripped from the model once it was removed from the test container.

Results of the drain test are summarized below: 
August 13, 1996

Page 2

\section{Wetted ID-69 Tube Assembly \\ With the rod spacing wider then the design pattern}

\begin{tabular}{|l|l|l|l|l|}
\hline Temperature & Smooth removal & Weight change & Shaking removal & Weight change \\
\hline $\begin{array}{l}\text { Room Temperature } \\
\text { prior to starting the } \\
\text { test. }\end{array}$ & 1618.3 grams & & 1618.3 grams & \\
\hline $400^{\circ} \mathrm{F}$ & 1620.5 grams & 2.2 grams & 1620.5 grams & 2.2 grams \\
\hline $450^{\circ} \mathrm{F}$ & 1620.3 grams & 2.0 grams & 1620.5 grams & 2.2 grams \\
\hline $500^{\circ} \mathrm{F}$ & 1620.1 grams & 1.8 grams & 1620.4 grams & 2.1 grams \\
\hline $600^{\circ} \mathrm{F}$ & 1620.1 grams & 1.8 grams & 1620.1 grams & 1.8 grams \\
\hline & & & & \\
\hline
\end{tabular}

During fabrication of the model, some warping of the rods occurred, causing the spacing to be wider at the bottom than the design pattern. A second drain test was tried using a hose clamp to hold the rods closer to their design pattern. While installing the hose clamp 0.8 grams of sodium were squeezed out of the model. At $400^{\circ} \mathrm{F}$ with 2.2 grams of sodium was held up in the model.

When the hose clamp was then removed, it was observed that the rods stayed close to their design. Another drain test was performed at $400^{\circ} \mathrm{F}$ with 2.3 grams of sodium held up.

\section{ID-69 Tube Assembly}

With the rods held in their designed pattern

\begin{tabular}{|l|l|l|}
\hline Temperature & Smooth removal & Weight change \\
\hline $\begin{array}{l}\text { Room Temperature prior to } \\
\text { starting the test. }\end{array}$ & 1645.8 grams & \\
\hline $400^{\circ} \mathrm{F}$ (with hose clamp) & 1648.0 grams & 2.2 grams \\
\hline & & \\
\hline $400^{\circ} \mathrm{F}$ (without hose clamp) & 1620.6 grams & 2.3 grams \\
\hline
\end{tabular}


August 13, 1996

Page 3

With the rods closer to their design pattern the sodium was evenly distributed along the length of the model, between the rods. It appears that in the ID-69 assembly, the sodium would not tend to drain to the bottom half of the fixture.

Verification of the $6-\mathrm{kg}$ balance was made by weighing a 200 -gram weight after completion of the sodium drain test. The balance gave a reading of 200.0 grams.

Conclusions:

- For all temperatures from $400^{\circ}$ to $600^{\circ} \mathrm{F}$, using either a smooth removal or shaking removal, the weight change was $2.0 \pm 0.2$ grams.

- With the rods squeezed together with a hose clamp the holdup was still within the range of $2.0 \pm 0.2$ grams.

- The major difference between the wider spaced rods and clamped rods was the location of the sodium along the length. In the ID-69 assembly, the sodium would tend to distribute along the full length of the tubes.

Sincerely

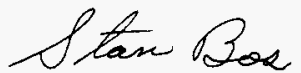

Stanley Bos

Atomic and Molecular Chemistry

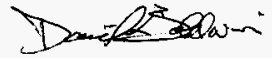

Concurrence
$8 / 13 / 96$ 


\section{TEST FOR SODIUM RETENTION \\ OF THE \\ ID-69 SPRING BLOCK}

SCOPE

The ID-69 steel spring block weighing 19 lbs has many tortuous paths and has the potential to retain a large amount of sodium. This test wi 11 quantify the amount of sodium retained by an unwetted spring block.

METHOD

A container has had a flexible heating cable wrapped around it and had several layers of insulation fixed over the cable. The container will be used to melt sodium maintaining the temperature at $204^{\circ} \mathrm{C}\left(400^{\circ} \mathrm{F}\right)$ in a glovebox with an argon atmosphere. The spring block will be placed in the sodium and allowed to heat soak till it is the same temperature as the sodium. It will be removed and allowed to drain and then harden as it cools to betow the sodium melting temperature of $95.5^{\circ} \mathrm{C}\left(204^{\circ} \mathrm{F}\right)$. The assembly will then be removed from the glovebox in a wrapping to maintain the purity of the sodium and weighed. When compared to the original, the difference will be the amount of sodium retained. This will be repeated with a "chimney" around the spring block as it is removed from the container in an effort to simulate the conditions as found just above the FSF sodium pool.

EQUIPMENT

Type and model scale

Type of Thermocouple (T/C)

WEIGHT of the ID-69 SPRING BLOCK

Max cap. (2ikg) $45 \mathrm{lbs}$. I.cel 16 Ohues Heavy Dity Solution Bulane

WEIGHT of the Container

Weight of sodium in container
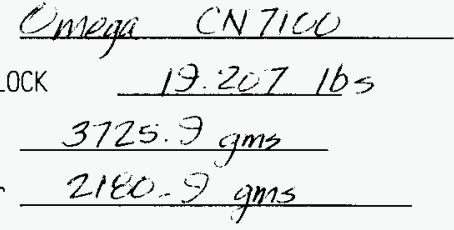

\section{PROCEDURE}

1. Record the information required for the scale and $T / C$ in the above section.

2. Heat the sodium in the container melting it. Observe the reaction of the surface of the sodium to confirm the condition of the glovebox atmosphere. Record the reaction of the surface i.e. does it cloud or does it clump?

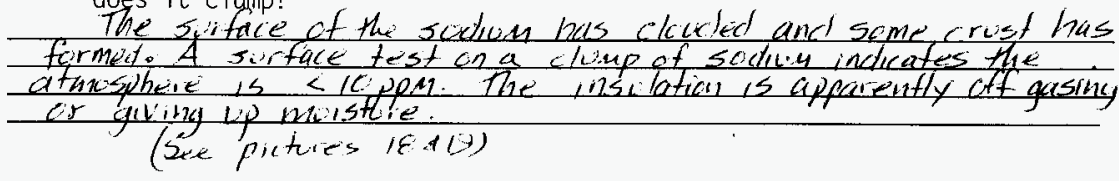


3. Continue to heat the sodium to $204^{\circ} \mathrm{C}\left(400^{\circ} \mathrm{F}\right)$. 61 mins to heat to $2 \mathrm{C} 4^{\circ} \mathrm{C}$

4. Insert the spring block in to the heated liquid sodium and record the amount of time to heat soak the spring block by measuring the amount of time for the sodium to $\mathrm{cool}$ and reheat to $204^{\circ} \mathrm{C}\left(400^{\circ \mathrm{F}}\right)$. Sochum coclecd

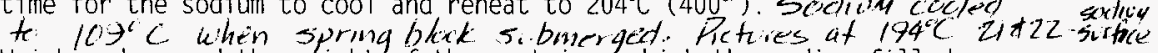
5. Weigh and record the weight of the container which the sodium filled 23024 at $204 \%$ spring block will be transported from the glovebox to the scale.

$$
\text { l'sed plastic the weight "Weight of the container }
$$

6. Remove the spring block and allow it to drain and the sodium to solidify. Wrap the sodium filled spring block in an inerted container and seal it. Transport to the scale. Spring bleck left sifting cul a platferm of

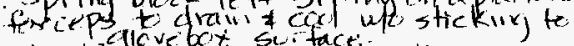

7. Weigh and record the weight of the spring bletke, container and sodium. 19. 330 , 1bs weight of spring block with sodium step 7 . $19.207 / 6$ sweight of spring block from step 1 .

.123163 55.8 A quins

8. Transport the spring block back into the glove box and place the spring block back into sodium and reheat to $204^{\circ} \mathrm{C}\left(400^{\circ \mathrm{F}}\right)$.

\section{see nute ter clisrussion}

9. Place a chimney to create a heated space above the sodium large enough to contain the spring block while it drains.

10. Weigh and record the weight of the container which the sodium filled spring block will be transported from the glovebox to the scale.

same as ste 5 Weight of the container

11. Remove the spring block and allow it to drain and the sodium to solidify. Wrap the sodium filled spring block in an inerted container and seal it. Transport to the scale.

12. Weigh and record the weight of the spring block, container and sodium.

19.325 / bs weight of spring block with sodium step 12.

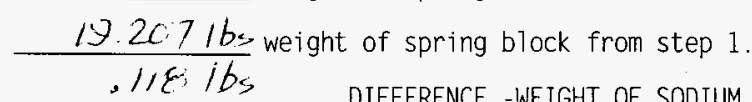
$5 ;<$ gims.

DIFFERENCE -WEIGHT OF SODIUM RETAINED

13. Transport the spring block back into the glove box and store it.

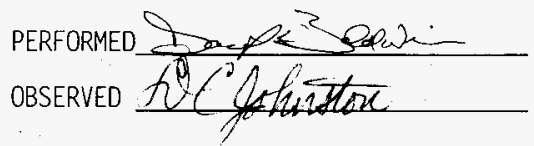



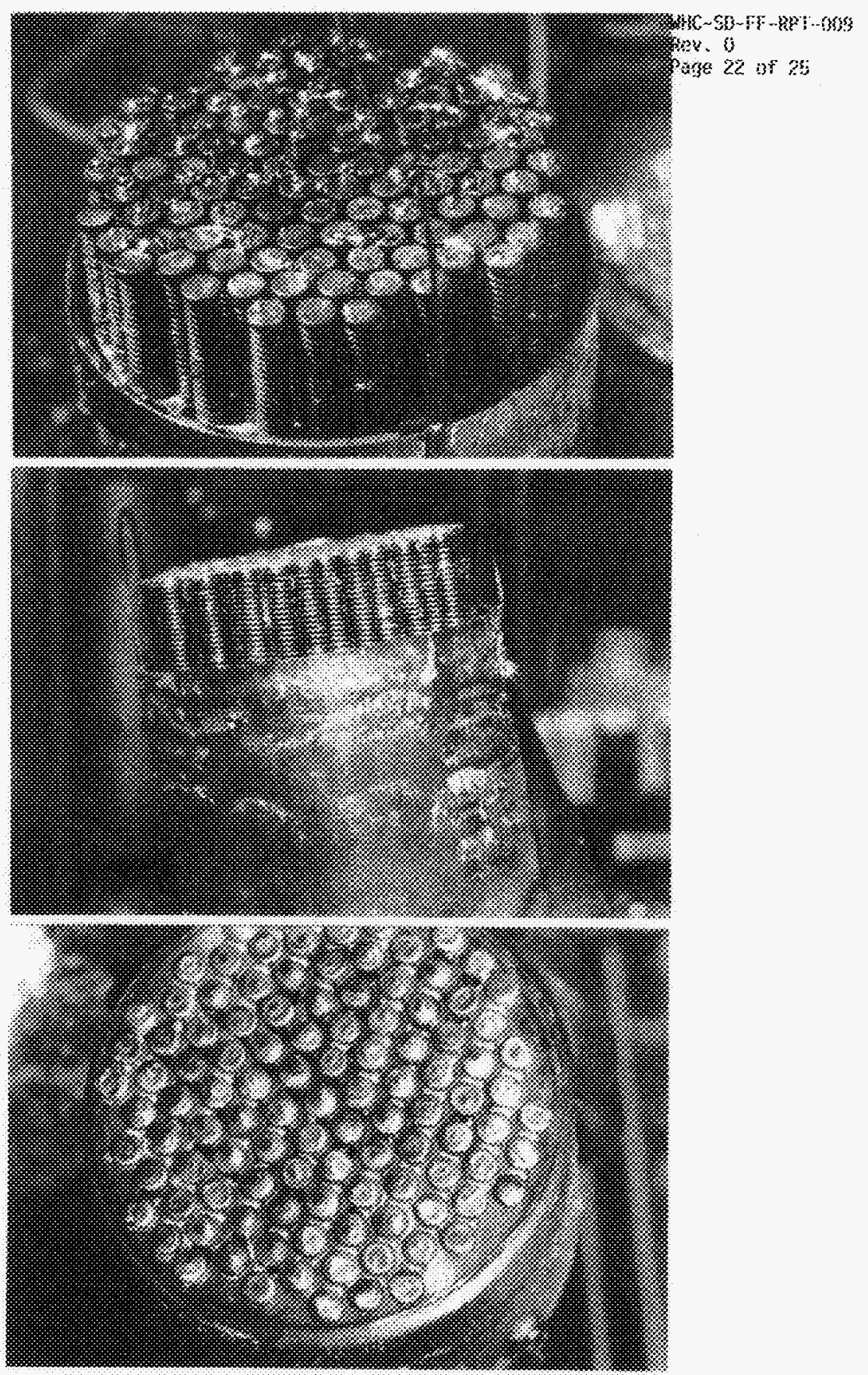

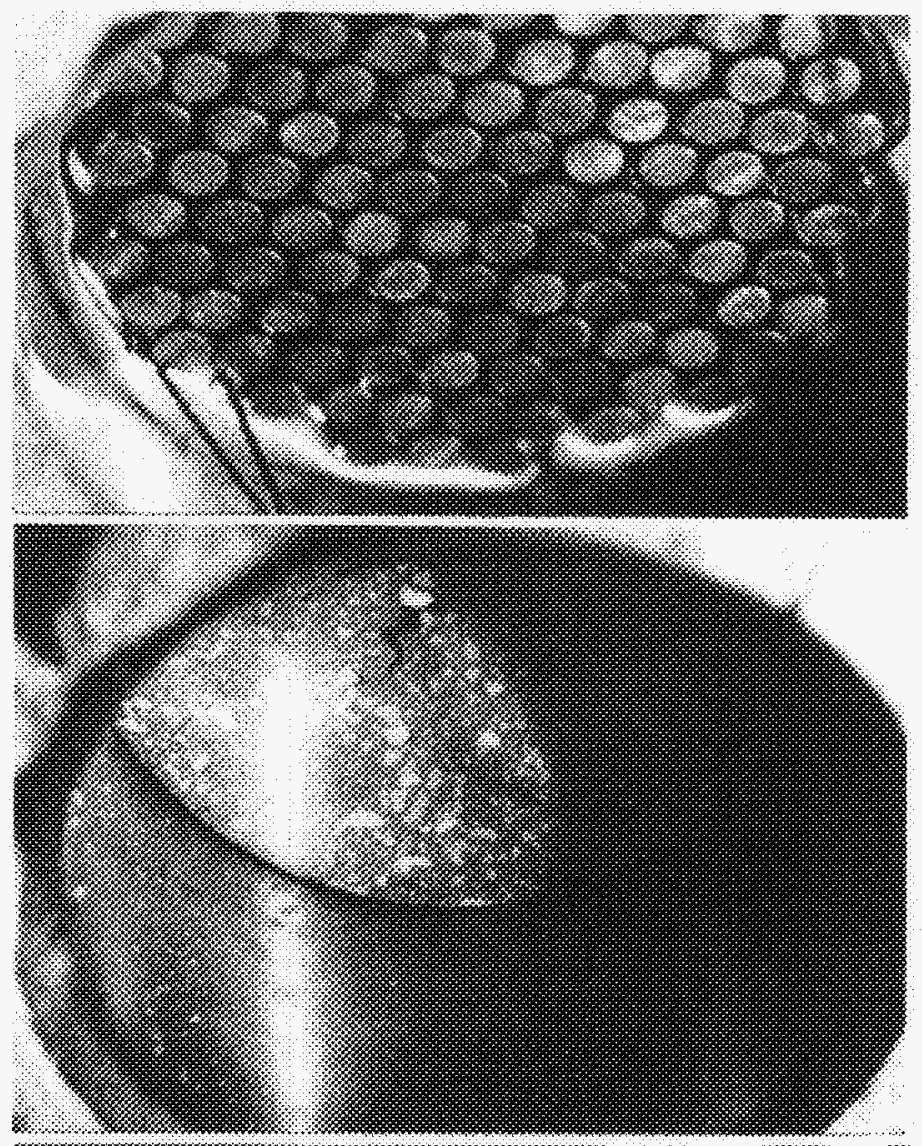

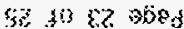

0 'xay
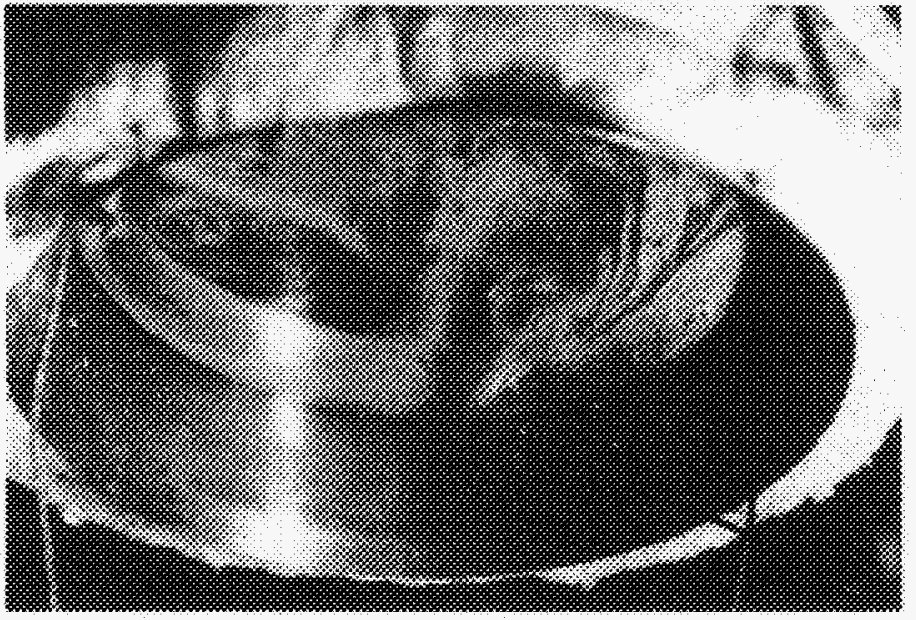


\section{Pacific Northwest National Laboratory}

August 29, 1996

\section{D.C. Johnston}

Westinghouse Hanford Co.

Box 999 Mail Slot N2-02

Richland, WA 99352

Dear Mr. Johnston:

Measurements of sodium hold up in an ID-69 spring block has been completed. Testing was done in an inert atmosphere glove box containing $<1 \mathrm{ppm}$ oxygen and water. A 4-liter stainless steel beaker was wrapped with heating cable and two layers of wet wrap insulation. To dry the insulation the container was then heated to $200^{\circ} \mathrm{C}$ overnight then raised to $400^{\circ} \mathrm{C}$ for one hour. During the early part of the drain testing, it was observed that this drying time was insufficient and a layer of sodium oxide formed on the sodium surface. This layer was scrapped away and did not appear to impact the testing.

Reagent grade sodium was prepared by melting it in a bottom draining container. By draining from the bottom, sodium metal was separated from the sodium oxide covering found on reagent sodium. Calculation as follows showed that about 2140 grams of sodium would be required to cover the spring block.

Volume of spring block Depth of sodium to cover Inside diameter of beaker Actual weight of beaker, heater and insulation
$1067 \mathrm{cc}$ 6.5 inches $\quad(16.51 \mathrm{~cm})$ $63 / 16$ inches $(15.72 \mathrm{~cm})$ 3726 grams

$$
\begin{aligned}
& 3.14 *(15.72 / 2)^{2} * 16.51=3203 \mathrm{cc} \\
& 3203-1067=2136 \mathrm{cc} \quad \text { (using density of } 1) \quad 2136 \text { grams of sodium }
\end{aligned}
$$$$
3726+2136=5862 \text { grams ( target weight of sodium) }
$$

Actual weight of heater and sodium

Actual weight of sodium added to the container
5907 grams

2181 grams

Weighing the spring block was accomplished on an Ohaus beam balance with a capacity of 45

$$
\text { Battelle Boulevard - P.0. Box } 999 \text { a Richland, WA } 99352
$$


D.C. Johnston

August 29, 1996

Page 2

\pm 0.001 pounds. It was necessary to take weight measurement outside of the glove box do to the size of the balance. Prior to adding sodium the spring block weighed 19.207 pounds.

The sodium was preheated to $205^{\circ} \mathrm{C}\left(400^{\circ} \mathrm{F}\right)$ and the spring block lowered into the container. Adding the spring block cooled the sodium to $109^{\circ} \mathrm{C}$, forty five minutes were required to reheat to $205^{\circ} \mathrm{C}$. The spring block was withdrawn, being careful not to shake off any sodium. A 10 to 15 gram (estimate) pool of sodium remained on top of the springs. The spring block was allowed to cool overnight and observations were made the following morning. About $90 \%$ of the outer ring of springs were frozen in place by sodium, about $2 / 3$ of the remaining springs were stuck. It appeared that very little sodium was held up inside the spring block.

Wrapping the spring block in a plastic bag, it was removed from the glove box for weighing. With the addition of the sodium the spring block weighed 19.330 pounds, an increase of 0.123 pounds ( 55.8 grams ).

Returning the spring block to the glove box the drain test was repeated, this time shaking any sodium off the top and pulling the block up into an aluminum foil curtain to improve drainage in the cooler glove box atmosphere. Weight of the spring block after the second test was 19.325 pounds or 0.118 pounds ( 53.6 grams ) of sodium.

\section{Conclusions:}

- Even though varying amounts of sodium can be held up on top of the spring block, there was very little difference in the overall sodium holdup, with the two very different methods of extraction.

- Very little sodium appears to hang up inside the spring block.

- The mass of stainless steel in the spring block retains enough heat that sodium draining is not affected by lifting into a cooler atmosphere.

Sincerely

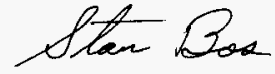

Stanley Bos

Atomic and Molecular Chemistry

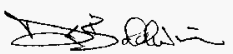

Concurrence $8 / 29 / 96$ 


\section{DISTRIBUTION SHEET}

\begin{tabular}{|c|c|}
\hline Distibuticn & From IEMC dRME Engine \\
\hline
\end{tabular}

Project TitleN Work Order

$$
\text { 1DG9 Sodiun Drain Experimenf }
$$

\begin{tabular}{|c|c|c|c|c|}
\hline Name & MSIN & $\begin{array}{l}\text { With } \\
\text { Attach. }\end{array}$ & \begin{tabular}{|l|} 
EDT/ECN \& \\
Comment
\end{tabular} & $\begin{array}{l}\text { EDT/ECN } \\
\text { Only }\end{array}$ \\
\hline$D$ knuston & $\mathrm{N}_{2} \mathrm{Cl}$ & $x$ & & \\
\hline$P M M^{3}$ Guness & $\sqrt{2}-02$ & $y$ & & \\
\hline k' Brehm & $N 2-\overline{56}$ & $x$ & & \\
\hline s H H ler & $\left.N_{4}^{\prime}\right)-C 2$ & $x$ & & \\
\hline itation File 22 & $\sqrt{2-12}$ & $E D T, 5 D$ & 01 & 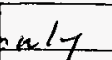 \\
\hline 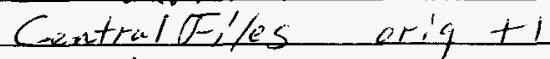 & A3 -88 & $x$ & & \\
\hline BM uballice & $N z-12$ & EDT,SD & & \\
\hline
\end{tabular}

